\title{
Spatial regulation of synthetic and biological nanoparticles by DNA nanotechnology
}

Zhongqiang Yang, Huajie Liu and Dongsheng Liu

NPG Asia Materials (2015) 7, e192; doi:10.1038/am.2015.59; published online 26 June 2015

Correction to: NPG Asia Materials advance online publication, 27 February 2015; doi:10.1038/am.2015.2

After online publication of this article, the authors noticed an error in the reference section.
The correct reference of this article should have read as below.

39. Prinz, J., Schreiber, B., Olejko, L., Oertel, J., Rackwitz, J., Keller, A. \& Bald, I. DNA origami substrates for highly sensitive surfaceenhanced Raman scattering. J. Phys. Chem. Lett. 4, 4140-4145 (2013).

The authors apologize for any inconvenience caused. 